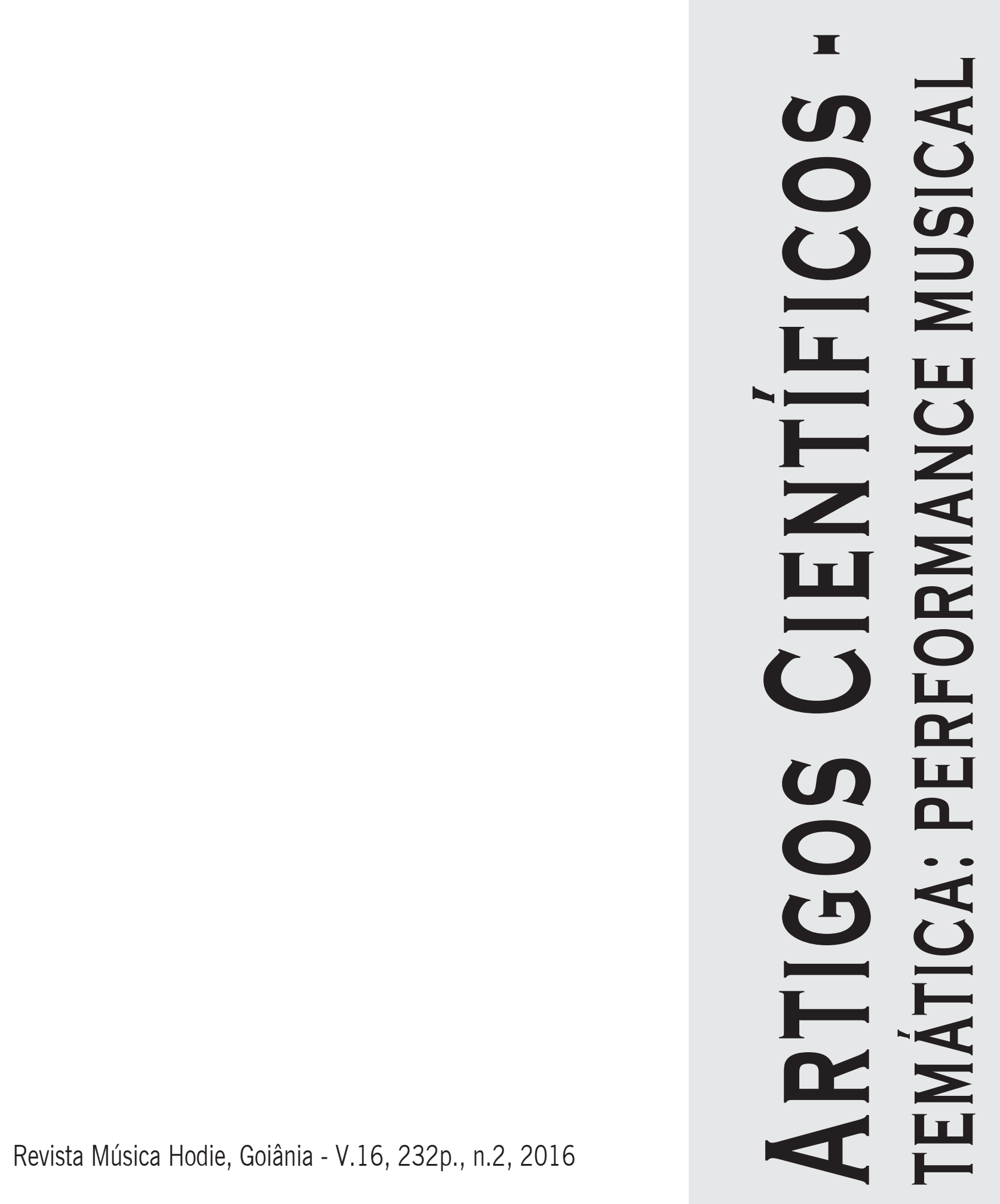




\title{
Escolhendo o repertório coral: uma tarefa de regentes?
}

\author{
Matheus Cruz Paes de Almeida (Universidade Estadual de Londrina, Londrina, PR, Brasil)
}

matheuscpa.cruz@gmail.com

\begin{abstract}
Resumo: O artigo discute primeiramente a formação do regente coral nos aspectos de técnica vocal, técnica de regência, técnica de ensaio ou gestão de ensaio, elaboração ou adaptação de arranjos e o papel do regente na escolha do repertório coral. O artigo também propôs uma prática não somente centrada no regente, mas voltada para o interesse dos coralistas. Esta proposta foi desenvolvida através de um estudo de caso com o coral Nossa Voz de Flórida-PR. A participação destes coralistas na escolha do repertório foi um processo que trousse motivação, identidade e boas lembranças para o grupo. O referencial teórico considerou trabalhos de Amato (2010), Bartle (2003), Cox (2006), Devenny (2014), Lakschevitz (2007), Kerr (2007), Vieira e Ray (2007), Schmeling (1999), entre outros.

Palavras-chave: Escolha de repertório coral; Prática coral; O papel do regente coral.
\end{abstract}

Selecting the choir repertoire: the conductor's job?

Abstract: This article discusses the formation of the choir conductor in the aspects of vocal technique, conducting technique, assay technique and management of test, development or adaptation of arrangements and the role of the conductor in the choice of choral repertoire. The article also proposed a practice not only centered on the conductor, but focused on the interest of the choristers. This proposal was developed through a case study with the choir Nossa Voz of Florida-PR. The participation of these choristers in the choice of repertoire was a process that trousse motivation, identity and good memories for the group. The theoretical framework considered Amato works (2010), Bartle (2003), Cox (2006), Devenny (2014), Lakschevitz (2007), Kerr (2007), Vieira and Ray (2007), Schmeling (1999), among others.

Keywords: Choice of choral repertoire; Choir practice; The role of choir conductor.

Seleccionando el repertorio del coro: la labor del conductor?

Resumen: Este artículo se describe la formación del director de coro en los aspectos de técnica vocal, la realización de la técnica, técnica de ensayo y manejo de pruebas, desarrollo o adaptación de los acuerdos y el papel del conductor en la elección del repertorio coral. El documento también propone una práctica no sólo centrada en el conductor, pero se centró en el interés de los coristas. Esta propuesta fue desarrollada a través de un estudio de caso con el coro Nossa Voz de Florida-PR. La participación de estos coristas en la elección del repertorio fue un proceso que TROUSSE motivación, identidad y buenos recuerdos para el grupo. El marco teórico considerado Amato funciona (2010), Bartle (2003), Cox (2006), Devenny (2014), Lakschevitz (2007), Kerr (2007), Vieira y Ray (2007), Schmeling (1999), entre otros.

Palabras clave: Elección del repertorio coral; Los ensayos del coro; El papel de director de coro.

O artigo discute a formação do regente coral focando nas aptidões necessárias para a escolha do repertório, sendo este voltado para um coro específico: o coral Nossa Voz de Flórida-Pr. O texto também aborda como a participação dos coralistas na escolha deste repertório influenciou o trabalho do coro como um todo. O referencial teórico considerou trabalhos de Amato (2010), Bartle (2003), Cox (2006), Devenny (2014), Lakschevitz (2007), Kerr (2007), Vieira e Ray (2007), Schmeling (1999), entre outros. A principal conclusão em que chegamos foi que a motivação foi o agente mais evidente dessa nova proposta metodológica em relação a escolha de repertório para o grupo, à comunidade e ao regente.

\section{A formação do regente e a escolha do repertório}

As habilidades necessárias para o regente realizar um trabalho coral significativo são diversas. A técnica vocal certamente é um elemento crucial em sua formação; conseguir extrair de seu coro a sonoridade desejada é uma das habilidades que determinará a qualidade sonora desse grupo. Além desses aspectos, a técnica de regência é uma habi- 
lidade que também influencia nessa sonoridade e que possibilita uma comunicação entre coralista e regente de forma mais intimista e significativa. Figueiredo soma, a estas, outras habilidades como: "solfejo, treinamento auditivo, harmônico, análise musical, domínio de um instrumento e outros itens comuns a todas as atividades musicais" (FIGUEIREDO, 2007, p. 6).

Sabemos que todas essas capacidades são extremamente importantes na formação de um regente coral. Segundo Ramos (2003), além desses elementos há outros extremamente relevantes:

O exercício da regência pressupõe conhecimento na área de técnica vocal, ouvido apurado para as questões de afinação, timbre, precisão rítmica, desenvolturas para questões analíticas e musicológicas, domínio do repertório e das questões interpretativas de naturezas estilísticas, muita cultura geral, literária e artística. Além disto, na maioria dos casos, é necessário ter uma apurada técnica de resolução de problemas, seja através de atividades educativas, seja apenas sendo capaz de muita clareza para a identificação e criação de estratégias para a obtenção de resultados. Muitas vezes, em se tratando de Regência Coral, são necessárias qualidades pessoais não exatamente musicais, como certa capacidade de gerência de problemas entre pessoas, de liderança de longo prazo associado a um certo carisma que pode ter inúmeras faces ou mesmo a de ser o empresário de seu próprio grupo, entre outras que poderão sempre surgir e se manifestar de acordo com circunstâncias especiais. (RAMOS, 2003, p. 1)

À frente de um coro, o regente certamente necessitará de todas essas habilidades listadas acima. Destacamos, porém, a necessidade de o regente lidar com a resolução de problemas tanto musicais como extramusicais em seu coro. Estratégias específicas de ensino minimizam problemas musicais relativos à afinação, à dicção, ao ritmo, à harmonia; vocalises com fragmentos do repertório antecipam dificuldades e já propõem soluções; problemas rítmicos podem ser percutidos no corpo, de uma forma que os cantores consigam assimilar e transferir essa experiência para a peça realizada.

Problemas extramusicais podem estar relacionados a questões administrativas, a questões de relacionamento interpessoal, e também à ação que o coro desempenha na vida das pessoas. Amato (2010) salienta que

o ofício da regência coral requer de seu praticante um conjunto de habilidades inter-relacionadas referentes não somente ao preparo técnico-musical, mas também à gestão e condução de um conjunto de pessoas que buscam motivação, educação musical e convivência em um grupo social. Adjacentes a tais habilidades estão os saberes interdisciplinares - educacionais, musicais, fonoaudiólogos, históricos, etc. -, os quais, em sinergia, conduzem a uma prática de canto em conjunto concomitantemente gratificante aos seus participantes e aos ouvintes, com desempenho social e musicalmente ativo. (AMATO, 2010, p. 5)

Mas, certamente, um grande desafio a ser enfrentado no trabalho coral é aquele relacionado à escolha do repertório. E aí nos perguntamos: esta tarefa, comumente realizada pelo regente, poderia ser compartilhada com os cantores?

Antes de tudo, pensemos em vários aspectos que podem interferir nesse processo de eleição das peças a serem cantadas. Em primeiro lugar, qual é a função desse coro na instituição à qual ele pertence? É coro que faz parte de empresa, de escola, de igreja? É coro comunitário, feminino, masculino, misto, de terceira idade, ou coro independente? Pode ser um coro que tenha sido criado com o propósito de formar novas plateias? O trabalho poderia ser então executado, inicialmente, por meio de um repertório comum a essa plateia e, em um segundo momento, ocorrer a inserção de um novo repertório. 
É sabido que o coro também pode ser utilizado como um rico espaço de educação musical para os coralistas. Conforme Penna (1990), "o canto coral é tido, com frequência, como instrumento privilegiado de musicalização” (PENNA, 1990, p. 68). Dessa forma, a tarefa do regente poderá ser desde alfabetizar musicalmente os cantores até propor a discussão de outros aspectos musicais. Neste caso, a ação do regente será totalmente pedagógica, oportunizando atividades com esse caráter didático.

De qualquer forma, levanta-se a questão se será o regente quem deverá escolher o repertório, pautado em sua experiência, em seu gosto pessoal, ou poderá levar em consideração a opinião dos coralistas, deixando-os participar desse processo de escolha.

Em busca de obter respostas baseadas em autores relacionados ao trabalho coral, a bibliografia apresentou propostas como a da regente Elza Lakschevitz. A regente apresenta a importância que o repertório escolhido tem na vida dos coralistas, afirmando que o repertório pode proporcionar desde elementos musicais até elementos sociais, educativos e culturais. E que é dever do regente lidar com essas escolhas, sem se esquecer de que o repertório também deve ser prazeroso de ser executado (LAKSCHEVITZ apud FIGUEIREDO, 2007, p. 49).

Nancy Cox (2006) apresenta alguns critérios para a escolha do repertório em um coro de escola. Dentre os critérios, a autora enfatiza que o regente deve refletir em sua análise sobre os elementos musicais que aquele repertório específico pode proporcionar aos alunos e como o repertório poderá auxiliá-los na ampliação de sua sensibilidade musical.

Outros elementos relacionados à escolha de repertório são levantados por Figueiredo (1990, p. 22). Ele mostra que o melhor caminho para a escolha do repertório, de acordo com ROE, "é escolher música autêntica que seja um bom exemplo de estilo, época, cultura e que contenha boa organização formal e qualidades expressivas" (FIGUEIREDO, 1990, p. 22).

De acordo com a proposta apresentada por DeVenny (2014, p. 78), encontrar as peças certas para seu grupo é uma tarefa demorada que requer tempo e cuidado, mas que faz parte desse trabalho do regente para se obter um bom resultado. No artigo, o autor lista inúmeras atividades que o regente deve buscar para realizar essa tarefa de escolher o repertório para seu grupo. Dentre elas, estar em contato com editoras de partituras, participar de congressos que possibilitem ouvir outros coros realizando um repertório variado, frequentar concertos de coros semelhantes ao seu e, por fim, ficar atento ao acervo de partituras do lugar onde trabalha.

Essa mesma proposta de escolha do repertório por parte do regente é apresentada pela regente Jean Bartle (2003, p. 182), que aponta os pontos cruciais para a escolha do repertório de coro infantil, mas que sem dúvida também pode ser aplicado à escolha do repertório de outros tipos de grupos corais:

Claramente, um das mais importantes e demoradas tarefas que um regente de um coro infantil deve fazer é escolher repertório adequado. Com um repertório digno, o coro tem o potencial de atingir grandes alturas artísticas. Com repertório pobre ou modesto, esse potencial nunca será alcançado. Crianças devem ser ensinadas apenas com o material mais valioso musicalmente. Para os jovens, apenas o melhor é suficientemente bom. Eles devem ser levados a obras-primas por meio de obras de arte. Uma peça que vale a pena sempre ajuda a criança a crescer musicalmente e colabora para desenvolver a beleza da voz da criança. Idealmente também irá beneficiar outras áreas de crescimento - estéticas, sociais, históricas, educacionais e políticas. (BARTLE, 2003, p. 182)

Além de todos esses aspectos, a elaboração de arranjos ou de adaptações tem sido, também, uma prática frequente entre os regentes. Neste artigo, ao mencionarmos os termos 
"arranjo" e "adaptação" teremos em mente as definições apresentadas por Bastos (2003). Segundo o autor, o arranjo é caracterizado pela "reestruturação de uma obra ou de um tema musical com a inserção de novos elementos, obtidos a partir de técnicas musicais especificas, como desenvolvimento temático, variação, polifonia, instrumentação harmonização e outras" (BASTOS 2003 apud VIEIRA; RAY, 2007, p. 10).

Ainda segundo o autor, "adaptação é transporte de uma obra musical para formações instrumentais ou vocais diferentes daquela para a qual foi composta, com a possibilidade de inserção de elementos estruturais que não constavam da versão original” (BASTOS 2003 apud VIEIRA; RAY, 2007, p. 10,).

Kerr (2007) apresenta outras considerações importantes sobre o que deve ser relevante para fazer um acordo

a minha intenção é criar uma peça adaptada às condições vocais específicas de um determinado coro, sem exigir mais do que aquilo que ele possa fazer espontaneamente, sem que ele seja obrigado a enfrentar textos estrangeiros, problemas de estilo ou tessituras que antes nunca precisou alcançar. (KERR, 2007, p. 131)

Como no Brasil há uma grande dificuldade de acesso a materiais impressos, os regentes se mobilizam realizando arranjos ou adaptações que se adequem à realidade de seus coros, em sua maioria coros amadores - um "coro formado por leigos", de acordo com Ramos, e que não recebe remuneração (RAMOS, 2003, p. 16).

\section{Estudo de caso}

Para a discussão deste artigo, foi realizado um estudo de caso do grupo "Nossa Voz" da cidade de Flórida, interior do estado do Paraná. A escolha do grupo, dentre outros fatores, deu-se por se tratar de um coro que estava sob a responsabilidade do próprio autor do estudo. O grupo era formado basicamente por mulheres, contendo apenas um homem, com pessoas de faixa etária superior a vinte anos e inferior a oitenta. Era um grupo pequeno que realizava obras a duas ou a três vozes, a maioria delas cânones ou melodias sobrepostas. Os ensaios aconteciam na Casa da Cultura da cidade todas as segundas-feiras, das 19h30min às 21h30min, num anfiteatro com capacidade para aproximadamente 150 pessoas, com um palco condizente com o tamanho do coro. Nesse espaço, havia uma sala em que guardávamos as partituras e o teclado utilizado nos ensaios. O coro contava com uma tecladista que nos auxiliava em todos os ensaios e apresentações. Era um coro comunitário, vinculado à Prefeitura Municipal, formado em fevereiro de 2010, com o objetivo inicial de proporcionar uma atividade musical para as pessoas da terceira idade ou acima de cinquenta anos. Como na época a procura não foi a esperada, abrimos novas vagas para pessoas da comunidade em geral, comerciantes, funcionários públicos, professores, enfim, a todos os que quisessem cantar e que tivessem idade superior a vinte anos.

No decorrer do primeiro ano, foi observada uma insatisfação dos cantores em relação ao repertório, que foi pensado inicialmente em oferecer aos coralistas uma grande variedade de estilos musicais, proporcionando uma ampliação de seu repertório pessoal. Considerando essa insatisfação e pensando em uma solução para esse descontentamento, tivemos a ideia de convidar os cantores para auxiliar nesse processo de escolha do repertório, como forma de motivá-los e também de motivar outros integrantes para o coro.

Como pudemos observar, a literatura pesquisada apresenta uma prática comum entre os regentes em relação à escolha do repertório. Sugere uma escolha pautada em um 
repertório amplo, diversificado, que proporcione aos coralistas uma grande variedade de estilos, gêneros e línguas; peças que eles sejam capazes de realizar bem e que possibilitem um desafio a ser vencido, sendo essa prática, tradicionalmente, tarefa exclusiva do regente. Contudo, apresentava-se-nos um problema cuja solução caberia a nós buscar: os coralistas não queriam realizar parte do repertório proposto. Nossos procedimentos, a partir daí, ganharam nova direção, buscando inserir os cantores nessa ação de escolha do repertório.

\section{Participação dos coralistas na escolha do repertório}

Na busca de encontrar autores que nos apoiassem nessa ação, deparamo-nos com uma experiência semelhante à nossa. A regente e professora Agnes Schmeling ${ }^{1}$ compartilha em seu artigo essa experiência com um coral de adolescentes; nele, a professora relata que "cada vez mais os cantores querem ser agentes do processo" (SCHMELING, 1999, p. 2). Considerando isso, ela sempre iniciava o ano letivo do coro discutindo com eles o que eles gostariam de cantar, quais eram as sugestões que eles traziam naquele ano. A partir dessas informações ela analisava e escolhia o repertório, pensando nas apresentações e na forma com que apresentaria essas escolhas ao grupo, mas sempre os envolvendo como membros ativos dessas escolhas.

Outra proposta de escolha do repertório que se aproxima do raciocínio que tentamos desenvolver é apresentada por Torres (2003, p. 67), quando destaca a atenção que os regentes devem ter em ouvir o que seus coralistas estão cantando e permitir que essas também sejam possibilidades de repertório.

A construção do repertório é uma constante motivação e elemento vital no processo de ensino e aprendizagem. Dessa forma, com "ouvidos atentos" ao que os coralistas cantam em suas rodas de violão, nos intervalos, ao que sugerem que seja cantado, ao que gostam, ao que faz parte de seu cotidiano [...]. (TORRES et al, 2003, p. 67 apud SILVA; FEZA; ARALDI; MIRANDA, 2007 p. 5)

Assim, as indicações de estar atento ao que os alunos cantam ou trazem de sugestão para dentro do ensaio são as ideias centrais das duas propostas apresentadas acima. Como podemos observar, essa participação dos coralistas na escolha do repertório traz para o grupo uma característica única, possibilitando ao grupo mais que uma afinidade entre os membros; dá-lhes uma identidade. Por esta razão, Igayara (2007) diz que

a escolha de repertório para um coro está intrinsecamente ligada à definição de sua identidade. A recusa ou a aceitação de uma música no repertório de um grupo coral passa pela discussão, por seus participantes, do que aquela obra acrescenta na identidade do grupo. (IGAYARA, 2007, p. 1)

É claro que o fato de os coralistas participarem da escolha do repertório de seu grupo não retira a autonomia do regente de escolher determinada peça para o grupo. O que estamos propondo é uma cooperação entre ambas as partes - regente e coralistas - para que dessa forma possa haver uma maior cumplicidade entre os membros participantes desse grupo; essa cumplicidade também pode ser entendida como mais um dos elementos formadores da identidade desse grupo.

Podemos dizer que a identidade de um grupo, como por exemplo, um grupo coral, é bastante influenciado pelas relações que cada membro tem consigo mesmo e com os outros. 
É importante considerar que cada um traz consigo experiências vividas com outras pessoas que vão se somando e se acomodando, formando a identidade daquele grupo. Na escolha do repertório, essas experiências individuais que cada um traz conseguem se tornar grandes possibilidades ao regente, quando são transmitidas por meio das sugestões de músicas, possibilitando ao regente refletir sobre a definição desse repertório; elegem um conjunto de peças que traz consigo a identidade de cada pessoa e que forma, depois, a identidade daquele grupo.

Quando esse processo de participação do coralista na escolha do repertório é executado e bem sucedido, certamente afloram nos coralistas sentimentos que os motivam a permanecer no grupo e os incitam a convidar outras pessoas a cantar nesse grupo, pois dessa forma eles se sentem partes integrantes das ações do grupo; a energia do ensaio fica melhor, as músicas fluem com mais leveza, oportunizando uma boa realização desse repertório.

Um dos sentimentos que conseguimos resgatar com essa prática da participação dos coralistas na escolha do repertório foi a motivação. Entendemos a motivação, nesse processo, como aquele registrado por Amato e Neto quando dizem sobre

um estado psicológico no qual o indivíduo tem disposição para realizar uma ação,
seja no trabalho, seja em qualquer esfera de sua vida. Na raiz latina da palavra, mo-
vere, encontra-se uma de suas características-chave, o movimento, a dinâmica, ou se-
ja, motivação não é algo implantado no indivíduo de forma permanente, mas sim um
processo contínuo em que fatores de diversas naturezas atuam, a partir da concreti-
zação dos desejos das pessoas, do cumprimento de suas metas e do atendimento de
suas expectativas (AMATO NETO, 2005). Para motivar, é preciso cultivar a autoesti-
ma individual, integrar a pessoa ao seu grupo de trabalho e fazê-la se sentir impor-
tante para o sucesso coletivo. (AMATO; NETO, 2009 p. 88)

Esse processo de cultivar esse espírito de motivação dentro do ensaio deve ser, sem dúvida, algo a ser encorajado. Acreditamos que esse processo motivacional teve seu advento, em nosso caso específico, com o processo de inserção dos coralistas na escolha do repertório, que ocorreu através da investigação por meio de um questionário. Nesse questionário perguntamos quais eram as músicas que eles gostariam de cantar no coro; cada cantor deveria nos fornecer dois exemplos delas. A outra pergunta que realizamos era por que eles gostariam de cantar aquela música no coro. Os resultados desse questionário levaram-nos a concluir que mais de oitenta por cento do coro sugeria músicas do estilo sertanejo. Os cantores relataram que gostariam de cantar esse tipo de música no coro porque remetiam a uma boa fase da vida, trazendo-lhes inúmeras lembranças.

Estudar experiências musicais a partir de lembranças de idosas pode mostrar uma construção com a música que foi feita com o passar dos anos, o que possibilita refletir sobre o que foi vivido. Mas, não uma vivência qualquer, esquecida, e sim a experiência que ainda hoje está presente, pois ainda tem o valor, ainda possui alguma significação. (MARQUES, 2010, p. 1003)

O pensamento de Marques (2010, p. 1003) foi identificado nos coralistas por meio do estilo sertanejo mencionado no questionário; nele, eles apresentam músicas desse estilo que remetem a experiências significativas em suas vidas. Cabe ressaltar que, neste trabalho, consideramos música sertaneja aquela que se caracteriza como "gênero não urbano" ou "a música do sertão norte e nordeste” (SOBOLL, 2007, p. 24), que tem geralmente como acompanhamento o violão, o acordeão e principalmente a viola caipira. 
Essa discussão do repertório aconteceu quando fomos comentar sobre as respostas que eles haviam colocado no questionário. Relatamos a eles que todas aquelas sugestões seriam utilizadas como material sugestivo de escolha do repertório do semestre seguinte; não seria possível cantar algumas daquelas músicas naquele semestre, obviamente pelo tempo de preparação que exigiam e pela quantidade de repertório que era escolhido por semestre.

Logo após esse momento, iniciou-se a procura por arranjos ou por adaptações das músicas relacionadas a esse estilo musical predominante nas sugestões apresentadas pelos coralistas - o estilo sertanejo.

Nessa procura pelas músicas referentes a esse estilo musical, não foram encontrados muitos arranjos. Dos que foram encontrados, alguns eram a quatro vozes e outros eram adaptações que, como os arranjos, não eram adequados para aquele grupo. Por consequência, iniciamos uma confecção de arranjos e de algumas adaptações dos arranjos encontrados que viesse ao encontro da necessidade da formação que estava sendo adotada para aquele grupo, possibilitando realizar esse repertório sertanejo de uma forma positiva e estimulante.

É bom lembrar que essa prática de confecção de arranjos tem-se tornado comum no Brasil e, como afirma Soboll, seu uso

tem sido quantitativamente superior em comparação ao uso de composições originais para coro. Por isso, é fato comprovado que a escrita de arranjos se tornou uma prática frequente e quase necessária para os regentes de coros amadores. (SOBOLL, 2007, p. 9)

Essa afirmação de Soboll (2007) indica-nos mais um elemento necessário à formação do regente coral: a prática de realizar arranjos. Sem dúvida, a partir da prática de confeccionar arranjos veio também a necessidade de realizar adaptações para os arranjos já feitos. Com o coral "Nossa Voz", realizamos essas duas práticas: a de confeccionar arranjos e a de realizar adaptações. Primeiro, foi a prática de confeccionar arranjos das músicas que não possuíam ou que não havíamos encontrado arranjos prontos, que foram "Tocando em Frente" e "Luar do Sertão". A outra prática foi a de realizar adaptações de arranjos encontrados. Alguns deles eram escritos para quatro vozes, o que nos impossibilitava realizá-los. Dessa forma, após a adaptação desses arranjos, foi possível realizar essas peças. Um exemplo dessa prática foi com o arranjo da música "Asa Branca” de Luiz Gonzaga, arranjo de Marcos Leite a quatro vozes, que foi adaptado para três, o que possibilitou ao coro realizá-lo.

Essa prática de confeccionar arranjos e adaptações ocorreu no coral "Nossa Voz" devido também à impossibilidade de acesso a materiais que fossem passíveis de serem realizados com o grupo. Com isso, comprava-se a argumentação de Pereira, ao mencionar a

necessidade de escrever um arranjo que se ajuste bem àquele coral em particular, quer seja pela formação do grupo, por uma exigência do repertório ou mesmo por um desejo dos cantores. Se há falta de repertório, falta também quem escreva arranjos de boa qualidade para diferentes formações (para 3, 4 ou 5 vozes, coros femininos, masculinos, etc.), organizados em diferentes graus de dificuldade e que este repertório esteja sendo constantemente renovado. (PEREIRA, 2006, p. 2 apud SOBOLL, 2007, p. 9)

Em nosso caso, pudemos confirmar a necessidade de o regente ter essa habilidade de realizar a prática de confeccionar arranjos e adaptações, que se constitui um procedimento comum em nosso país, pela falta de material impresso.

Com a iniciativa de inserir os cantores na escolha do repertório, identificamos inúmeros pontos positivos que comprovam a eficácia desta ação. Com a inserção desse reper- 
tório buscado a partir das escolhas deles, houve motivação para não mais faltarem aos ensaios. Observamos que os números de faltas aos ensaios diminuíram significativamente.

Outro fato importante observado foi aquele relativo à chegada sem atraso ao ensaio. Eles alegavam que chegavam atrasados por inúmeros fatores, mas principalmente por não quererem realizar o aquecimento vocal. Em determinado ensaio, tivemos de explicar-lhes que para bem realizarmos aquele repertório escolhido em conjunto, precisaríamos realizar um aquecimento que nos facilitasse realizá-lo. Dessa forma, não mais chegaram atrasados ao ensaio e, quando isso acontecia, se justificavam, assumindo assim uma postura completamente positiva e responsável.

Observamos também elementos positivos não só dentro do coro, mas fora dele. Identificamos, por exemplo, um aumento considerável no número de pessoas da plateia após a apresentação desse repertório. Notamos as pessoas mais empolgadas e motivadas em ir aos concertos, questionando quando seriam e a que horas seriam os concertos seguintes. Outro fator importantíssimo foi a entrada de novos coralistas para o coro, fortalecendo a autoestima do grupo e os motivando a realizar cada vez melhor o repertório.

Foi constituído um repertório que continha elementos que eram possíveis e adequados ao grupo. As letras das músicas sertanejas remetiam em sua maioria a uma história com a qual os coralistas geralmente se identificavam, possibilitando uma reflexão sobre esse texto que favorecia imensamente a interpretação da peça. Outro fator importante nesse processo pôde ser explorado a partir do ritmo do baião, que apareceu em inúmeras músicas, propiciando um treinamento rítmico. Em algumas peças, a ênfase foi na harmonia, onde trabalhamos aspectos de equalização do som e afinação.

Sem dúvida, a exploração desses elementos nesse repertório sertanejo proporcionou um grande crescimento ao grupo, fortalecendo os vínculos afetivos dos membros, aprimorando elementos musicais pertinentes a esse estilo e também ampliando sua atenção para outros estilos.

\section{Conclusão}

A bibliografia consultada apontava uma prática comum o regente visto como o único agente na escolha do repertório. Essa ação do regente de definir o repertório de seu grupo, pautado em suas experiências e buscando oferecer-lhe peças que, em sua opinião, pudessem levar o grupo a um melhor desenvolvimento musical é um procedimento corriqueiro, tradicionalmente utilizado pelos regentes, como indica a literatura.

Em nossa prática, quisemos ousar um pouco mais, convidando os cantores a participar dessa escolha. Por meio de um questionário, tivemos acesso às opiniões deles sobre que repertório gostariam que fosse executado no coro; depois de analisadas, algumas peças foram selecionadas para a execução com o grupo.

Os resultados dessa eleição de nova proposta metodológica em relação ao procedimento de escolha de repertório trouxeram benefícios ao grupo, à comunidade e ao regente. Com relação ao grupo, identificamos inúmeros pontos positivos advindos dessa ação: os cantores se sentiram mais valorizados e, consequentemente, essa ação os motivou a não mais faltarem aos ensaios, a não chegarem mais atrasados e principalmente a quererem cada vez mais apresentar as peças que faziam parte de suas vivências. Com isso, a comunidade, ou seja, a plateia se identificou com esse repertório e começou a ficar cada vez mais presente nos concertos; esse fator foi observado pelos coralistas como um grande elemento motivacional para eles. Quanto ao regente, ter a oportunidade de vivenciar essa prática tão 
pouco explorada em nosso meio foi um grande desafio. Entendemos este desafio como algo muito positivo, porque percebemos o quanto podemos errar ou nos equivocar quanto à escolha do repertório para um grupo, e como essa escolha afeta tanto positivamente quanto negativamente. Com a participação dos coralistas, acreditamos que as chances de não agradar aos coralistas e à plateia é, se não totalmente, bastante minimizada. Dessa forma, o regente pode ter um ambiente agradável e propício para a realização de um bom ensaio e para executar muita música.

Verificamos, então, que a inserção dos coralistas na escolha do repertório foi uma iniciativa extremamente positiva e trouxe muitos benefícios para o grupo. O crescimento de todos foi notório, mas a motivação percebida nos pareceu o ponto crucial para que permanecessem cantando.

\section{Nota}

1 Na época da escrita do artigo, a professora atuava junto ao Movimento Coral da Universidade do Vale do Rio dos Sinos/RS.

\section{Referências}

AMATO, Rita de Cássia Fucci. A Regência além da Regência: Liderança e Inteligência Emocional em Maestros. In: XXX Encontro Nacional de Engenharia de Produção. Maturidade e desafios da Engenharia de Produção: competitividade das empresas, condições de trabalho, meio ambiente. São Carlos, SP, Brasil, 12 a15 de outubro de 2010.

BARTLE, Jean Ashworth. Sound Advice - Becoming a better children's choir conductor. Oxford University Press, USA, Feb 5, 2003.

COX, Nancy. Repertoire Standards: Children's Choirs - Selecting Choral Literature for Children's Choirs: A Closer Look at the Process - Part I. National Repertoire \& Standards Chair. Choral Journal. 2006.

DEVENNY, David P. Student Times - Repertory and Programming: Guidelines for the Young Conductor. September, 2014. Disponivel em <http://cmed.faculty.ku.edu/450/DeVenney.pdf >. Acessado em: 17 Outubro 2015.

FIGUEIREDO, C. A. et al. Ensaios: Olhares Sobre a Música Coral Brasileira. Organização Eduardo Lakschevitz. Rio de Janeiro: Centro de Estudos de Música Coral, 2007.

FIGUEIREDO, Sergio Luiz Ferreira de. O Ensino Coral Como Momento de Aprendizagem: A Prática Coral Numa Perspectiva de Educação Musical. Dissertação de Mestrado. Universidade de São Paulo. Escola de Comunicações e Artes da Universidade de São Paulo. São Paulo, 1990.

FUCCI AMATO, Rita de Cássia; AMATO NETO, João. A motivação no canto coral: perspectivas para a gestão de recursos humanos em música. In: Revista da Associação Brasileira de Educação Musical, 22., 2009, Porto Alegre. Revista da ABEM. Porto Alegre, V. 22, 87-96, set. 2009.

IGAYARA, Susana Cecília. Discutindo o Repertório Coral. In: Congresso Nacional de Educação Musical, 2007, São Paulo. Anais... São Paulo, 2007.

KERR, Samuel et al. Ensaios: Olhares Sobre a Música Coral Brasileira. Organização Eduardo Lakschevitz. Rio de Janeiro: Centro de Estudos de Música Coral, 2007. 
MARQUES, Jaqueline Soares. Experiências musicais: um estudo a partir das lembranças de idosas. In: CONGRESSO NACIONAL DE EDUCAÇÃO MUSICAL, 19., 2010, Goiânia. Anais... Goiânia: UFG, 2010, p. 1002-1010.

OLIVEIRA, Vilmar Pereira de. Diga-me o que ouves e te direi quem és: a influência e as contribuições da música no processo de construção da identidade de jovens da Região Metropolitana de Belo Horizonte. 2012. 95 f. Monografia (Conclusão do curso) - Pontifícia Universidade Católica de Minas Gerais, Faculdade de Psicologia, 2012. Belo Horizonte, 2012.

PENNA, M. L. Reavaliações e buscas em musicalização. 2. Edição. São Paulo: Loyola, 1990.

RAMOS, Marco Antônio da Silva. O Ensino da Regência Coral. Tese de Livre-docência. Escola de Comunicações e Artes da Universidade de São Paulo, 2003. São Paulo: USP, 2003.

SCHMELING, Agnes. Cantar e conviver - uma experiência com um grupo coral de adolescentes. In: VIII Encontro Anual da Associação Brasileira de Educação Musical, 2002, Natal, RN. Anais... Natal, RN: ABEM, 2002.

SILVA, Michele Juliana de Carli Anselmo da; FEZA, Aline Pedro; ARALDI, Juciane; MIRANDA, Maria de Jesus Cano. Música na Educação Especial: um relato de experiência do projeto de extensão Atividades Alternativas Para Pessoas Com Necessidades Especiais. In: I Encontro Anual da Associação Brasileira de Educação Musical, Maringá, Pr. Anais... Maringá, Pr, 2007.

SOBOLL, Renato Stephanes. Arranjos de Música Regional do Sertão Caipira e sua Inserção no Repertório de Coros Amadores. Tese de Mestrado. Universidade Federal de Goiás - Escola de Música e Artes Cênicas, 2007. Goiânia: UFG, 2007.

VIEIRA, Gabriel; RAY, Sônia. Ensino coletivo de violão: Técnicas de arranjo para o desenvolvimento pedagógico. In: XVI Encontro Anual da Associação Brasileira e Educação Musical e Congresso Regional da ISME na América Latina, 2007. Anais... João Pessoa, 2007.

Matheus Cruz Paes de Almeida - Estudante de inglês e música no Johnson County Community College (USA) onde participa como tenor do coro da graduação em música. Matheus concluiu a pós-graduação em regência coral pela Universidade Estadual de Londrina-Pr (UEL) e a graduação em Educação Musical pela Universidade Estadual de Maringá-Pr (UEM). Teve seu artigo sobre canto coral publicado na revista da Associação Brasileira de Educação Musical (ABEM) edição 2014. Nos últimos cinco anos tem se dedicado ao estudo da regência e do canto, participando de festivais em todo o Brasil e recentemente nos EUA. Seus últimos trabalhos foram com coros infantis, juvenis, adulto, e de terceira idade. 